\title{
Ways to optimize process of modernization of trans-Siberian railway using digital economy technologies
}

\author{
Maria Samarina ${ }^{1}$, and Ekaterina Bondarchuk ${ }^{1, *}$ \\ ${ }^{1}$ Irkutsk State Transport University, 15, Chernyshevskogo str., Irkutsk, 664074, Russia
}

\begin{abstract}
The article discusses the issues of improving measures to optimize the process of modernizing the Trans-Siberian Railway using digital economy technologies. The digital economy provides for the implementation of a number of measures that stimulate the introduction of information and telecommunication technologies in most of the economic sectors of Russia. In the new interpretation, three components of the "Digital Economy" methodology are noted: information infrastructure of e-business, network e-business, e-commerce. All of these components are also part of the Digital Railroad Bratskoe. The railway is the backbone of the entire transport complex of the Russian Federation and is of great socioeconomic, political and defense importance. Compared to other modes of transport, railway transport is determined not only by the large value of the main economic indicators, but also by the volume of transportation work performed, both in freight and passenger traffic. The technological and economic effects from the development and implementation of digitalization projects for both freight and passenger transportation have been determined. A comparative analysis of the used services based on digital technologies was carried out for the predicted economic effect. The project "Digital Railway" was analyzed, in particular, one of the pilot projects "Digital Depot", implemented on the basis of the service locomotive depot SLD Bratskoye. The effectiveness of this measure is difficult to fully assess due to the relatively short implementation period. The first data for calculating the technical and economic efficiency are analyzed; a forecast for the future is presented.
\end{abstract}

Keywords: Digitalization, railway transport, CRM system, customer focus, efficiency

\section{Introduction}

In modern society, issues related to the prospects for the development of the digital economy and affecting the interests of both economic entities and ordinary people are becoming more and more relevant. Today, we can talk about the active development of digital technologies with the continuation of this process in the near future, as a result of which these trends cannot be ignored for many areas. The transport sector will not be an exception, as a result of which this issue should be studied in more detail [8].

It is difficult to imagine a person's life without digital technologies that contribute to increasing the competitiveness of the transport industry, improving interaction with customers, taking into account their needs in order to understand what proposal should be developed, and approve new services based on them for demand.

\section{Problem Statement}

The fundamental factor for mastering the achievements of digitalization in accordance with the Long-term development program of the Russian Railways company is considered as the possibility of creating a truly unified information space for freight transportation and logistics in order to increase the profitability of the entire freight market, logistics business in particular, without unforeseen costs arise [1].

In the modern world, the Digital Railroad Model of the Russian Railways Company is a special matrix of service blocks in which certain categories of automated solutions are placed in conjunction with aspects of the digital model of a business project.

The structure of the digital railway is presented in the following areas:

1. Passenger transportation: mobile application, ticket sales, Wi-Fi, information services for travelers, analytical reporting CRM.

2. Freight transport: digital exchange of wagons, $4 \mathrm{PL}$ logistics, multimodal transport, paperless technologies, CRM analytical reporting.

3. IT services: catalog of IT services and SLA.

4. ACS: complex automation.

5. IT Infrastructure: Continuity Services.

6. Motion control: intelligent motion control system, paperless technology.

7. Management of railway infrastructure: maintenance of infrastructure as per condition.

Corresponding author: samarina-mashenka@mail.ru 
8. Customer services: mobile services (CRM, BigData), etc. [2].

\section{Research Questions}

It will be possible to achieve the efficiency of the production activity of each of the participants in the transportation market if we ensure a truly high-quality fulfillment of the obligations assumed. These are fully agreed with the owner of the infrastructure of applications for the transportation of goods, the movement of wagons that belong to operators, as well as other owners of railway rolling stock, seeking minimum costs. This in turn directly depends on the volume of existing traffic in accordance with a single technology for organizing this process, avoiding serious violations [4].

As you can find out from the analysis of global technological trends, digital technologies contribute to the creation of special conditions in order to make adjustments to the classical models of doing business, to help with the discovery of new opportunities in absolutely all directions, in particular:

1) quick and easy access to the services provided for the transportation of goods;

2) predictive analytics of clients, development of proposals taking into account the actual needs of the target audience, which will appreciate the new services, services;

3) creation of new programs to attract organizations of the Russian Railways company, other enterprises, other types of transport infrastructure, in order to achieve a complete catalog of services;

4) introduction of Russian Railways directly into the customers' logistics system, based on joint planning of shipment, subsequent transportation of finished products, careful and fast delivery of goods, taking into account the actual need of the entire production process of customers who are interested in long-term cooperation [7].

\section{Purpose of the Study}

The purpose of this study is to assess, both from a technological and economic point of view, the possibilities of applying digital achievements at Russian Railways, in particular, on the Trans-Siberian Railway.

The program provides for a fairly large list of activities, each in its own way reflecting a different degree of automation.

In order to competently implement end-to-end coordinated automated technology, it is important to organize a single information space in an industry such as transport, so that it is possible to establish effective interaction of all interested participants in the transportation process. These are the automated control system of owners and customers, the operator, and the carrier, which is directly Russian Railways. As a result, the aspects associated with artificial intelligence and Big data technology will be really widespread for the automation of these processes.

\section{Research Methods}

Based on the purpose of this work, theoretical and quantitative methods were chosen as research methods. Due to the fact that the digitalization of the company's activities is taking place relatively recently and in completely different directions at the same time, it is quite difficult to quantify many indicators [3]. The main research method was theoretical, which made it possible to analyze the Strategy of Russian Railways within the framework of the digitalization section. In addition, the concept for the implementation of a complex scientific and technical project "digital railway" was chosen as the basic document of the study. The application of the quantitative method within the framework of the analysis of the dynamics of changes in indicators characterizing the operation of the depot became possible on the basis of the study of the Bratskoye digital depot project. This method was applied to assess the first results obtained since its commissioning, data for a period of 10 months.

\section{Findings}

The analyzed data on the directions of digital transformation in Russian Railways are presented in Table 01.

According to the data presented in the table above, one of the projects within the Digital Railway is the creation of the Digital Depot by the LocoTech holding. Having analyzed the Digital Depot project, which really corresponds to the concept of the Russian Railways company, as well as Transmashholding JSC regarding digital initiatives, in particular, Digital Railway, Smart Locomotive, which made it possible to make a choice regarding the Vikhorevka Vostochno- Siberian Traction Directorate, where AC electric locomotives "Ermak" were delivered [5].

An important aspect of monitoring the Digital Depot project is considered as the urgent need to increase the objectivity of data on the existing state of the locomotive fleet at absolutely all levels of management of maintenance processes, repair work, the ability to organize technological support for employees when making important decisions, automate processes associated with training, restoration, operations for the assembly and disassembly of parts, related equipment that is used.

A similar principle should be followed when the maintenance of the linear infrastructure takes place after a preliminary analysis of the current technical condition, which allows you to subsequently achieve acceleration, subsequent reduction in the cost of design, construction work, reduction in operating costs, and implementation of planned projects.

It is supposed to carry out competent automation of the terminal and warehouse complex in order to introduce innovations, ensure the presence of robots in the warehouse, various sensors. That make it possible to draw up a plan, and subsequently take into account the use of available resources that will be useful in certain circumstances on a long-term or short-term basis. 
Table 01. List of services organized on the basis of digital technologies (up to 2025)

\begin{tabular}{|c|c|c|}
\hline Direction of digital transformation & Services & Projected economic effect \\
\hline $\begin{array}{l}\text { Implemented CRM system to ensure full } \\
\text { interaction with every interested client }\end{array}$ & $\begin{array}{l}\text { A personal approach to each client, taking } \\
\text { into account the previously gained experience } \\
\text { of cooperation, based on current needs, } \\
\text { including the sale of complex services in the } \\
\text { transport sector, receiving confirmation of } \\
\text { applications on a convenient Internet portal } \\
\text { with a clear interface }\end{array}$ & $\begin{array}{l}\text { Increasing the share of rail } \\
\text { transportation, as well as } \\
\text { generating income from the use of } \\
\text { additional services }\end{array}$ \\
\hline $\begin{array}{l}\text { Multimodal electronic system that functions } \\
\text { directly in the passenger segment }\end{array}$ & $\begin{array}{l}\text { complex transportation of clients "from door } \\
\text { to door", using third-party carriers from other } \\
\text { types of the transport sector on the market }\end{array}$ & $\begin{array}{l}\text { Increase in commission income, as } \\
\text { well as the ability to ensure the } \\
\text { consolidation of traffic in one } \\
\text { place, in order to facilitate future } \\
\text { monetization, increase loyalty } \\
\text { indicators, and trust of each } \\
\text { passenger, regardless of their age, } \\
\text { gender, social status }\end{array}$ \\
\hline $\begin{array}{l}\text { Intelligent systems that allow you to } \\
\text { establish competent management of the } \\
\text { transportation process }\end{array}$ & $\begin{array}{l}\text { digitalization of the work of all represented } \\
\text { stations and service of clients interested in } \\
\text { cooperation at the points of unloading and } \\
\text { loading }\end{array}$ & $\begin{array}{l}\text { Increasing the speed of forecasting } \\
\text { traffic, reducing the influence of } \\
\text { the human factor, increasing the } \\
\text { productivity of traction rolling } \\
\text { stock, reducing losses from non- } \\
\text { schedule delays and train stops }\end{array}$ \\
\hline "Smart locomotive" and "digital depot" & $\begin{array}{l}\text { An open service, which provides information } \\
\text { about the manufacturer, user, directly to the } \\
\text { service organization, reporting accurate and } \\
\text { accessible information about the current state } \\
\text { of the rolling stock, taking into account } \\
\text { automated and remote diagnostics, high- } \\
\text { quality repair work, if necessary, without } \\
\text { waiting for the deadline of the schedule } \\
\text { drawn up in advance }\end{array}$ & $\begin{array}{l}\text { The ability to reduce the cost of } \\
\text { service, taking into account the } \\
\text { long period between repairs, as } \\
\text { well as making efforts to prevent } \\
\text { unplanned downtime }\end{array}$ \\
\hline
\end{tabular}

A separate block of the entire program is the aspect associated with the optimization of corporate processes, taking into account the introduction of electronic circulation of documents, tax monitoring with access to information from the tax service, digital personnel service, services. They allow you to quickly find qualified and experienced specialists, minimize the time spent on execution routine operations, which will help to increase labor productivity, reduce the time needed to search for candidates for vacancies, and reduce administrative costs directly [6].

For example, the Digital Depot project fully contributes to the achievement of the criteria of the target KGE (readiness for operation) when specifying economic indicators, downtime for planned types of service. As a result, it can be called a truly unique project of the entire organization, the implementation of which will make it possible to correct the existing nuances during the operation of locomotives, to obtain a visible effect from not only reducing penalties for the CGE, but also reducing direct and overhead costs on the network.

The principle of organizing repair work by the example of the Digital Depot project consists of the following elements:

- diagnostics;

- controlled repair process;

- control over personnel;

- transparent ITC management system;

- automated release to the line.
At the same time, each of the stages, in turn, is subdivided into smaller operations, thereby allowing carrying out a whole range of measures aimed at more efficient organization of the depot operation. Thanks to this project, it was planned to solve a number of problems encountered in practice and which led to economic losses.

Among such problem areas are:

- inappropriate use of the time factor in repair activities;

- low labor productivity;

- irrational use of labor;

- high rate of fines;

- low indicators of KGE, etc.

The introduction of any technology involves investment. To assess the effectiveness of an investment project for the implementation of a CRM system, the fundamental principles are modeling flows, resources and cash over periods, a comprehensive accounting of external and internal factors in the implementation of the project, determining the effect by comparing the expected investment results and costs.

The standard payback period for this project is considered less than 3 years, which makes it quite attractive.

A fairly short payback period is possible if the mandatory list of requirements is fulfilled according to the organization of the process. In this case, the economic effect will manifest itself in reducing the time for types of repairs, changing the form of workers' wages, and eliminating unproductive time. 


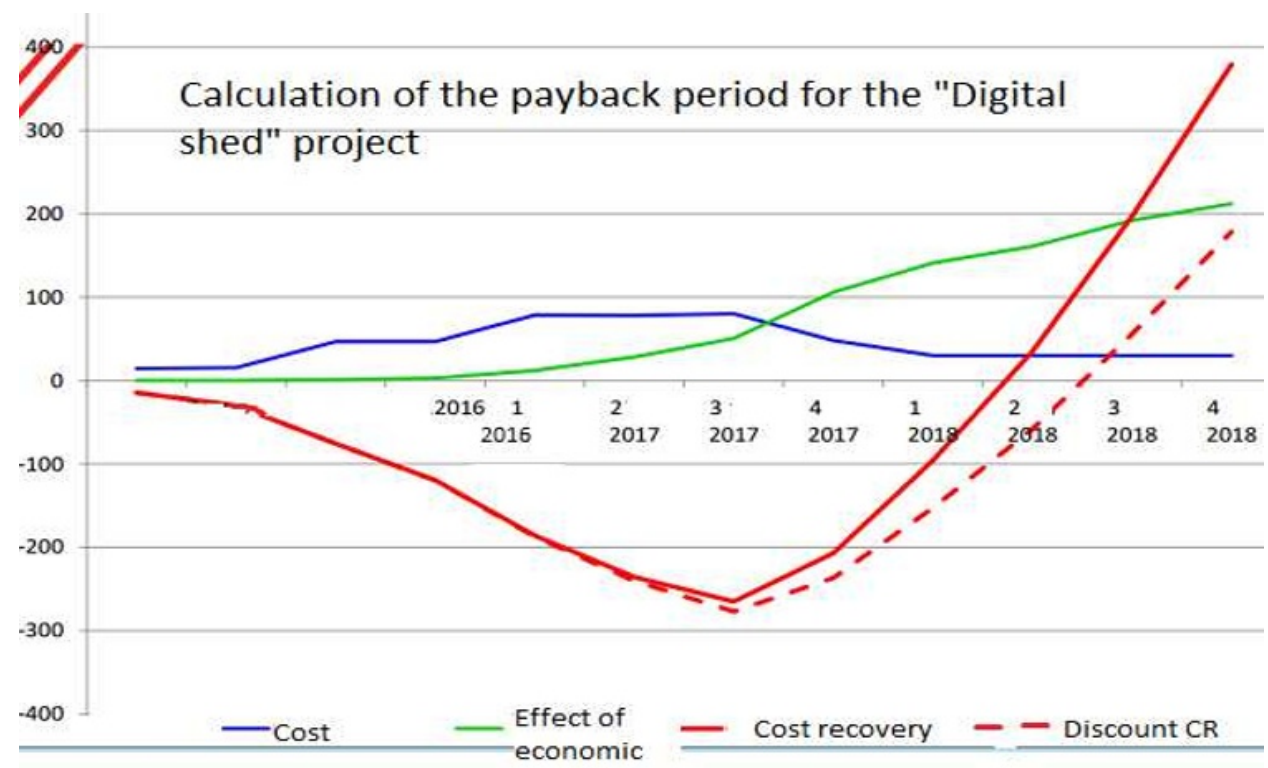

Figure 01. Predicted calculation of the payback period of the Digital Depot project

The main requirements for the personnel are the uninterrupted delivery of business travelers to the place of work. With regard to equipment, there is budget approval for a one-time supply and constant replenishment of an irreducible stock of linear equipment, as well as its installation on a locomotive at TR-1, TR-2, and HP.

Indicators of goods and materials are introduction of a simplified procedure for the purchase and reconciliation of invoices - directly through the TD, as well as the approval of new norms for writing off goods and materials.

At the moment, it is not entirely advisable to talk about the attainability of this indicator. During the first months of operation of the pilot project, the following results were obtained.

The effect expected from the implementation of this project is most pronounced in the time spent on repair work and the number of sections. This relationship is shown in the figure below.

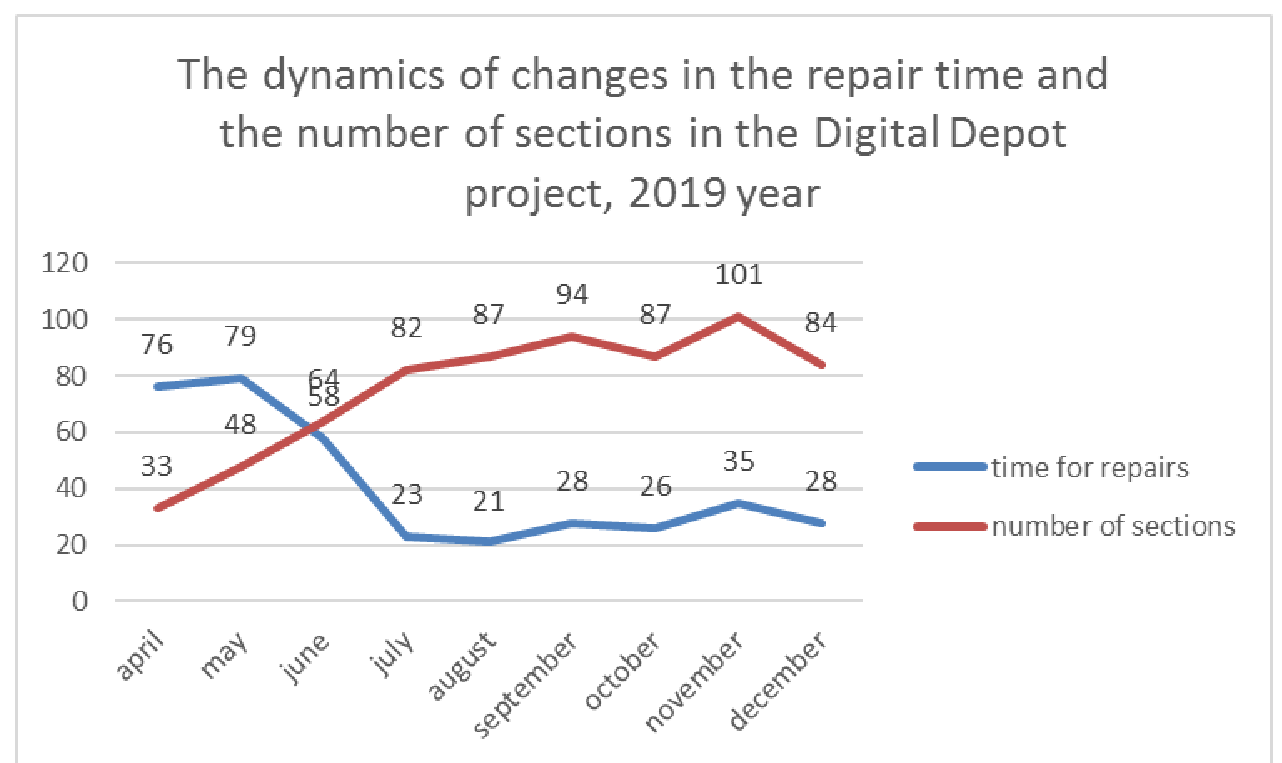

Figure 02. The dynamics of changes in the repair time and the number of sections in the Digital Depot project 2019 year

As you can see from the figure above, the amount of time for repair work is reduced, while the number of sections increases. A record value was reached in November with 101 sections. The relationship between the indicators shown in the figure above is also confirmed by the correlation analysis carried out earlier. According to him, the R-squared value is 0.87 , which indicates a close relationship between these indicators. In the future, the time indicators for repairs are also planned to be reduced to possible values, while the quality of work does not suffer, and labor productivity increases. The performance indicator for this period, according to the ratio of the time spent to the volume of work performed, varies from 0.4 to 3.4. According to the planned indicators, labor productivity should grow by $30 \%$. In the future, this manifests itself in the number and amount of fines associated with the AGE indicator. 
Table 02. Comparison of data on the time of work and the number of work performed before and after the implementation of the Digital Depot project

\begin{tabular}{|l|c|c|c|c|c|c|}
\hline \multirow{3}{*}{$\begin{array}{c}\text { Indicator } \\
\text { name }\end{array}$} & \multicolumn{6}{|c|}{$\begin{array}{c}\text { Types of repair work carried out at st. Bratskoe } \\
\text { (Digital Depot project) }\end{array}$} \\
\cline { 2 - 7 } & $\begin{array}{c}\text { maintenance } \\
\text { work - } 1\end{array}$ & \multicolumn{2}{c|}{$\begin{array}{c}\text { line } \\
\text { maintenance - 2 }\end{array}$} & \multicolumn{2}{c|}{$\begin{array}{c}\text { unscheduled } \\
\text { maintenance }\end{array}$} \\
\cline { 2 - 7 } & $\begin{array}{c}\text { actual } \\
\text { value }\end{array}$ & $\begin{array}{c}\text { target } \\
\text { value }\end{array}$ & $\begin{array}{c}\text { actual } \\
\text { value }\end{array}$ & $\begin{array}{c}\text { target } \\
\text { value }\end{array}$ & $\begin{array}{c}\text { actual } \\
\text { value }\end{array}$ & $\begin{array}{c}\text { target } \\
\text { value }\end{array}$ \\
\hline $\begin{array}{l}\text { Repair } \\
\text { time, hours }\end{array}$ & 64 & 18 & 1.5 & 0.3 & 21 & 4 \\
\hline $\begin{array}{l}\text { Number of } \\
\text { sections, } \\
\text { pcs }\end{array}$ & 40 & 130 & - & - & - & - \\
\hline
\end{tabular}

At the same time, the availability factor also tends to decrease from 0.950 to 0.914 . The amount of fines for the AEG is therefore reduced. In the most optimistic scenario, fines for some locomotives can be avoided.

The pilot includes over 30 different technological and organizational solutions combined into one system. They will improve the efficiency of production processes without increasing the workload of employees.

The technical condition of the locomotive is the main resource with which the project works. In the short term, the implemented systems will make it possible to assess and predict the technical condition of components and assemblies, as well as to offer the optimal solution in terms of the time and volume of repairs.

The predicted result from the competent implementation of the entire project is an increase in the readiness factor for the operation of the fleet of existing locomotives that are under maintenance, repair work, which is up to $97 \%$ with the ability to talk about:

- an increase in the quality indicators of the direct maintenance and subsequent repair of the presented locomotives, contributing to a decrease in the time spent in the workshops by at least $50 \%$;

- guarantees of indicators of objectivity of results, allowing to establish control over the performance of maintenance operations, repair work in accordance with the technology that has been approved;

- the results of competently carried out diagnostics, which makes it possible to assess the technical condition of the existing locomotive, as well as those components that are part of it, allowing for operation, subsequent repairs and further maintenance, observing all necessary measures, safety measures;

- optimization of the system of well-functioning management of high-quality inventory items;

- introduction of automation of operations, allowing for restoration and repair work;

- reduction to the minimum idle time of wagons that must be sent for the carriage of goods.

\section{Conclusion}

The integration of all digital solutions into a single system is planned to be completed by the end of 2022 . Successful digital innovations will be replicated and implemented in other service depots, which will lead to a complete and perfect technological modernization of locomotive service maintenance throughout the country. Improving the operating model of information technology management is aimed at ensuring effective information technology management, ensuring transparency of costs and increasing labour productivity, which will optimize staff and achieve savings in procurement.

It is safe to say that digitalization is a truly global process that is actively taking place in many countries, making it possible to improve many areas, in particular, rail transport, which makes it possible to optimize transportation, the maintenance of the entire infrastructure, and the provision of comfortable conditions for interested passengers and owners' cargo for various purposes.

\section{Acknowledgments}

The work is printed at the expense of the state assignment on the topic "Improving the mechanism of interaction between polygon structures and regional centers of corporate governance by the example of the Eastern polygon of railways".

\section{References}

1. O.A. Alekseenko, I.V. Ilyin. Digitalization of the global world and the role of the state in the digital economy. Inform. Society, 2, 25-28 (2018)

2. V.S. Dubov. Indicators for assessing the development of the digital economy. Sci. through the prism of time, 7(16) (2018). Retrieved from: http://www.naupri.ru/journal/1116

3. A. Kitaev, I. Mironova, A. Pogodaeva, D. Sokolov, E. Guseva. Railway station 2.0: a new pattern for the development of digital railway. Int. J. of Open Inform. Technol., 5(2), 85-96 (2017)

4. A.A. Kudryashov, A.I. Sholina. Infrastructure of the digital economy. Actual probl. of the modern econ., 5, 25-32 (2018)

5. A.N. Menovshchikova, I.D. Belaya, O.V. Selina. Development of information economy in Russia. Actual probl. of modern econ., 3, 177-181 (2018)

6. A.S. Sagynbekova. Digital economy: concept, prospects, development trends in Russia. Theory. Pract. Innovat., 4 (2018). Retrieved from: http://www.tpinauka.ru/2018/04/Sagynbekova.pdf

7. I. Sokolov, A. Misharin, V. Kupriyanovsky, O. Pokusaev, Y. Kupriyanovsky. Robots, autonomous robotic systems, artificial intelligence and the transformation of the market of transport and logistics services in the digitalization of the economy. Int. J. of Open Inform. Technol., 6(4) (2018)

8. N.A. Stefanova. The concept and general principles of the formation of clusters of the digital economy in Russia. Azimuth of sci. res.: econ. and manag., 1, 237-241 (2018) 